\title{
Fluid-induced harm in the hospital: look beyond volume and start considering sodium. From physiology towards recommendations for daily practice in hospitalized adults
}

Niels Van Regenmortel ${ }^{1,2^{*}}$ (0), Lynn Moers ${ }^{3}$, Thomas Langer ${ }^{4,5}$, Ella Roelant $^{6,7}$, Tim De Weerdt $^{8}$, Pietro Caironi ${ }^{9}$, Manu L. N. G. Malbrain ${ }^{10}$, Paul Elbers ${ }^{11}$, Tim Van den Wyngaert ${ }^{12,13}$ and Philippe G. Jorens ${ }^{1,13}$

\begin{abstract}
Purpose: latrogenic fluid overload is a potential side effect of intravenous fluid therapy in the hospital. Little attention has been paid to sodium administration as a separate cause of harm. With this narrative review, we aim to substantiate the hypothesis that a considerable amount of fluid-induced harm is caused not only by fluid volume, but also by the sodium that is administered to hospitalized patients.

Methods: We show how a regular dietary sodium intake is easily surpassed by the substantial amounts of sodium that are administered during typical hospital stays. The most significant sodium burdens are caused by isotonic maintenance fluid therapy and by fluid creep, defined as the large volume unintentionally administered to patients in the form of dissolved medication. In a section on physiology, we elaborate on the limited renal handling of an acute sodium load. We demonstrate how the subsequent retention of water is an energy-demanding, catabolic process and how free water is needed to excrete large burdens of sodium. We quantify the effect size of sodium-induced fluid retention and discuss its potential clinical impact. Finally, we propose preventive measures, discuss the benefits and risks of low-sodium maintenance fluid therapy, and explore options for reducing the amount of sodium caused by fluid creep.

Conclusion: The sodium burdens caused by isotonic maintenance fluids and fluid creep are responsible for an additional and avoidable derailment of fluid balance, with presumed clinical consequences. Moreover, the handling of sodium overload is characterized by increased catabolism. Easy and effective measures for reducing sodium load and fluid retention include choosing a hypotonic rather than isotonic maintenance fluid strategy (or avoiding these fluids when enough free water is provided through other sources) and dissolving as many medications as possible in glucose $5 \%$.
\end{abstract}

*Correspondence: niels.vanregenmortel@uza.be

${ }^{2}$ Department of Intensive Care Medicine, Ziekenhuis Netwerk Antwerpen Campus Stuivenberg, Lange Beeldekensstraat 267, B-2060 Antwerp, Belgium

Full list of author information is available at the end of the article

\section{Introduction}

Intravenous fluid therapy is associated with a broad spectrum of detrimental consequences. Well-known examples are the different clinical problems associated with the use of $\mathrm{NaCl} 0.9 \%$ and specific colloid solutions [1-4]. The best documented and most serious side effect of fluid therapy remains fluid overload, which is an independent risk factor for morbidity and mortality in critically ill and 
surgical patients [5, 6]. Excessive fluid volume has always been considered the root cause of iatrogenic fluid overload and has become a major research topic in the fields of perioperative and critical care medicine. However, another important and thus far largely neglected factor is the administered amount of sodium $[7,8]$.

In the ICU, the largest burden of sodium is caused by maintenance fluid therapy prescribed to cover patients' daily needs for fluids and electrolytes [9-11]. Furthermore, a substantial amount of sodium comes from fluid creep, the abundant fluids administered as a vehicle for intravenous medication or to keep intravenous lines open [9]. Since $\mathrm{NaCl} 0.9 \%$ is very often used for this purpose, high amounts of sodium can be administered inadvertently $[9,10,12]$.

The aim of this narrative review is to draw attention to fluid retention caused by the large sodium amounts typically administered to hospitalized patients. We summarize the physiological background and explain why renal sodium handling is inefficient and energy-intensive. We attempt to quantify sodium-induced fluid retention and assess its clinical impact $[7,8]$. Finally, we discuss various preventive and therapeutic options, paying specific attention to avoidable sodium sources.

\section{The hospital is a "sodium-rich environment"}

The Intersalt study evaluated sodium intake in $52 \mathrm{popu}$ lations throughout the world and found a wide range of sodium excretion (and thus intake) with medians from 1 to $246 \mathrm{mmol}$ per day [13]. According to most health organizations, a healthy diet contains no more than $2.3 \mathrm{~g}$ $(100 \mathrm{mmol})$ per day and provides an ample daily water intake of 2-2.5 $\mathrm{L}$ for the efficient excretion of solutes. As a result, the mean sodium-to-water ratio of a healthy diet is around $40-50 \mathrm{mmol}$ per liter. When compared to normal dietary sodium intake, substantial amounts of sodium are being administered daily to hospitalized patients.

A significant source of sodium in the hospital is the extensive use of maintenance fluid therapy. A prospective single-day point prevalence survey, conducted in 46 Australian and New Zealand ICUs, demonstrated that maintenance and replacement fluids are responsible for $30.9 \%$ of the total daily sodium administration of $220 \mathrm{mmol}$ $(5 \mathrm{~g})$ and-contrary to common belief-a much more significant source of sodium than resuscitation fluids [10]. We confirmed that maintenance and replacement fluids are the largest source of sodium administration in a retrospective study in 14,654 patients, showing that these fluids accounted for a larger fluid burden than resuscitation fluids, blood products and enteral nutrition together [9]. Sodium burdens caused by maintenance fluid therapy have increased substantially due to the ubiquitous practice of prescribing isotonic solutions for this purpose. Table 1 illustrates the large difference from the sodium content of a healthy diet [14]. For example, even the amount of sodium in $2 \mathrm{~L}$ of Ringer's lactate exceeds the median daily sodium intake of the country with the highest sodium intake in the world.

A second major-this time unintentional-source of sodium in the hospital is the custom of dissolving medications in $\mathrm{NaCl} 0.9 \%$ to enable intravenous administration. Bihari et al. demonstrated that drug boluses accounted for $12.3 \%$ of total sodium administration and drug infusions for $8.6 \%$ [15]. We previously reported that fluid creep, the cumulative unintentional fluid volume used as a vehicle for dissolving medication or to keep intravenous lines open was the largest source of daily fluid administration, representing $32.6 \%$ of total fluid intake [9]. Both studies unmasked fluid creep as the largest source of inadvertent sodium administration in the hospital. The need to dissolve intravenous medication comes in addition to the fact that many medications

Table 1 Sodium burdens of maintenance fluid regimens with different intravenous isotonic and hypotonic solutions

\begin{tabular}{|c|c|c|}
\hline \multirow[t]{2}{*}{ Intravenous solution (sodium concentration per liter) } & \multicolumn{2}{|c|}{$\begin{array}{l}\text { Daily sodium intake if a typical amount of } 2 \mathrm{~L} \text { of this } \\
\text { solution is used as maintenance fluid }\end{array}$} \\
\hline & Sodium (g/day) & $\begin{array}{l}\text { Sodium (mmol/ } \\
\text { day) }\end{array}$ \\
\hline $1 \mathrm{~L} \mathrm{NaCl} 0.9 \%$ (3.5 g/154 mmol) & 7 & 308 \\
\hline 1 L PlasmaLyte ${ }^{\circledR}(3.2 \mathrm{~g} / 140 \mathrm{mmol})$ & 6.4 & 280 \\
\hline 1 L Ringer's lactate (3 g/130 mmol) & 5.9 & 260 \\
\hline $1 \mathrm{~L} \mathrm{NaCl} 0.45 \%$ in $\mathrm{G} 5 \%(1.8 \mathrm{~g} / 77 \mathrm{mmol})$ & 3.5 & 154 \\
\hline $1 \mathrm{~L}$ Glucion $5 \%{ }^{\circledR}(1.2 \mathrm{~g} / 54 \mathrm{mmol})$ & 2.5 & 108 \\
\hline 1 L Maintelyte ${ }^{\circledR}(0.9 \mathrm{~g} / 40 \mathrm{mmol})$ & 1.8 & 80 \\
\hline \multicolumn{3}{|l|}{ Clinical nutrition } \\
\hline Typical (par)enteral nutrition solution ( \pm 1 g/40-50 mmol) & $1.8-2.3$ & $80-100$ \\
\hline
\end{tabular}

G5\% glucose 5\% 
themselves contain sodium, mostly to make the active substance more soluble in water [16]. For example, valproate in its salt form is very soluble in water $(1: 0.4)$ compared to its minimal solubility (1:800) in acidic form. A comprehensive list summarizing the sodium content of most commonly used drugs in the ICU shows that antibiotics in particular contain large amounts of sodium [12]. Effervescent medicines are also well-known for their high sodium content [17].

\section{The physiological handling of an abrupt increase in sodium administration \\ Kidneys excrete a sodium load inefficiently, which leads to fluid retention}

As early as the nineteenth century, it was demonstrated that there is a delay of 3 days before the kidneys are able to excrete sodium at the rate of intake following abrupt sodium load $[18,19]$. Later experiments determined that healthy kidneys of normal volunteers on a low-sodium diet $(0.5 \mathrm{~g}$, or $\pm 20 \mathrm{mmol}$ per day $)$ adapted surprisingly slowly when sodium intake was increased to about $3.2 \mathrm{~g}$ per day ( $\pm 150 \mathrm{mmol}$ ) [20]. Five days were needed to realign renal excretion with intake, with only about half of the excess sodium intake being excreted on the first day. The positive sodium balance caused fluid retention and an increase in body weight of over $1 \mathrm{~kg}$. Once baseline dietary intakes were restored, it again took several days to lose the gained weight. This slow rate of renal sodium handling is remarkable considering that healthy kidneys filter the entire plasma volume six times per day. Yet, they seem unable to manage an additional sodium load of a few hundred millimoles above the usual dietary intake. From an evolutionary viewpoint, however, this makes perfect sense. Indeed, compared to the risks of dehydration and sodium loss, sudden (voluntary) peaks in sodium intake have been a virtually non-existent problem throughout evolution. It is thus understandable that herbivores and omnivores, including humans, favor the conservation of water and sodium at the expense of a poor ability to excrete sodium [21]. This is illustrated by the fact that the nephron lacks a dedicated mechanism for active sodium secretion, while the retention of sodium is the physiological centerpiece of aldosterone-mediated volume retention [22].

Retaining water is an energy-demanding, catabolic process After an episode of sodium gain, total body water osmolality needs to be restored by the accrual of free water. Counterintuitively, it is not water ingestion (thirstinduced or otherwise) that is the most important effector in realigning osmolality following increased salt intake $[23,24]$. Human subjects were even shown to ingest less water after a long-term increase in sodium intake [23].
The main mechanism for generating an endogenous water surplus is the ability of the kidneys to reduce free water loss by concentrating urine [23, 24]. Unfortunately, the reabsorption of solute-free water in response to an increased sodium intake comes at a price. Several studies showed that urine concentration requires the accumulation of urea in the renal medullary interstitium in order to deliver the necessary osmotic driving force.[23, 24] The release of extra urea is an energy-intense process that requires a marked, glucocorticoid-driven catabolic reprioritization and a higher energy expenditure [23, 25]. In animal studies, this process was even shown to contribute to body weight loss [24].

\section{Excreting solutes is difficult if not enough free water is provided}

Eventually, superfluous sodium will need to be excreted. In view of the evolutionary adaptations discussed above, the renal ability to concentrate sodium is limited to about two times the plasma sodium concentration. This is in sharp contrast to other solutes that can be concentrated 10 to 1000 times above their plasma value [21]. When the maximum level of renal sodium concentration is reached (250-300 mmol per liter), the kidneys require the ingestion of additional free water to increase urinary volume and excrete additional sodium [21]. Sodium excretion is thus more difficult when ample free water is unavailable [26]. Limited access to water is a typical condition of many surgical and critically ill patients. In recent decades, a marked shift in the incidence of ICU-acquired dysnatremias from hyponatremia to hypernatremia was observed in two large Dutch cohorts [29]. Responsible factors are suspected to include increasingly restrictive fluid policies, diuretic use and the use of sodium-rich infusions.

Moreover, apart from sodium, other solutes also need to be excreted. Many critically ill patients exert osmotic diuresis due to a disturbed glucose metabolism, osmotic therapies or increased urea levels caused by (hyper)alimentation and ongoing catabolism [27, 28]. The necessity of excreting solutes is the main reason why it is not desirable to omit hypotonic maintenance fluids when other sources of water are absent. Hypotonic solutions provide the free water necessary to excrete the sodium and other solute burdens that are common in hospitalized patients.

\section{It takes two to tango! What is the role of chloride?}

An important aspect is that sodium is usually co-administered with chloride. It is well-recognized that sodium chloride-but not other sodium salts such as sodium bicarbonate-causes renal vasoconstriction, leading to a decrease in renal blood flow and glomerular filtration rate [30,31]. This explains why, after a bolus of $2 \mathrm{~L}$ of 
Hartmann's solution ( $\mathrm{Na} 131 \mathrm{mmol} / \mathrm{L}, \mathrm{Cl} 111 \mathrm{mmol} / \mathrm{L}$ ), both water and sodium were excreted more efficiently than an equal amount of $\mathrm{NaCl} 0.9 \%$ [32]. The co-administration of sodium and chloride can be partially avoided by the use of balanced solutions (e.g., Ringer's lactate, Hartmann's solution), which could therefore be superior to $\mathrm{NaCl} 0.9 \%$ in terms of fluid retention. Balanced solutions typically contain $100-110 \mathrm{mmol}$ of chloride per liter compared to $154 \mathrm{mmol}$ in $\mathrm{NaCl} 0.9 \%$. However, in the discussion on sodium overload due to maintenance fluid therapy, the value of balanced solutions should not be weighed against the use of $\mathrm{NaCl} 0.9 \%$, but against the use of a hypotonic fluid strategy. Balanced isotonic solutions will still impose much higher sodium and chloride burdens than hypotonic fluids (see also Table 1) [9]. It is unlikely that the chloride content of even unbalanced hypotonic maintenance fluids (e.g., $\mathrm{NaCl} 0.18-0.45 \%$ in glucose or dextrose $5 \%$ ) cause much fluid retention, since their chloride levels are well below that of human plasma and approximate dietary intake. Notably, the advantage of balanced solutions over $\mathrm{NaCl} 0.9 \%$ is further reduced when the necessary potassium administration is provided in the form of potassium chloride (although this issue could be resolved by administering potassium phosphate) $[7,9,33]$.

\section{The clinical consequences of sodium administration}

\section{Compared to sodium-poor alternatives, sodium-rich} maintenance fluids lead to significant increases in fluid balance, independent of volume

Quantifying the effect size of sodium-induced fluid retention due to fluid therapy is challenging. Different experiments showed that $\mathrm{NaCl} 0.9 \%$ is excreted more slowly than more hypotonic solutions. However, these studies only assessed the short-term effect of a single-fluid bolus [32,34]. In a study conducted over six consecutive days, 12 surgical patients received $3 \mathrm{~L} /$ day of either $\mathrm{NaCl}$ $0.9 \%$ or dextrose $5 \%$ [35]. The $\mathrm{NaCl} 0.9 \%$ group retained around $1000 \mathrm{mmol}$ of sodium and developed a positive fluid balance exceeding $3 \mathrm{~L}$ as early as the second postoperative day. The dextrose arm experienced mild hyponatremia on the first postoperative day, which improved rapidly as negative fluid balances (approximately $2 \mathrm{~L}$ by day 4) developed. Unfortunately, the study design varied both fluid volume and sodium content, making it impossible to assess fluid accumulation by sodium administration separately.

Two of our own studies, the MIHMoSA and the TOPMAST studies, had the primary goal of measuring the effect size of sodium-induced fluid retention using two common maintenance fluid regimens. During the MIHMoSA crossover experiment, cumulative fluid balance was assessed in 12 healthy volunteers who refrained from any oral intake during two separate study periods of $48 \mathrm{~h}$. They were administered maintenance fluids with a sodium concentration of $154(\mathrm{Na154})$ or $54 \mathrm{mmol} / \mathrm{L}$ (Na54), administered at $25 \mathrm{~mL} / \mathrm{kg} /$ day [8]. Cumulative fluid balance after $48 \mathrm{~h}$ was $590 \mathrm{~mL}(95 \%$ CI 450-729) more positive in patients receiving Na154. Using an almost identical study design, the same fluids and similar infusion rates, the double-blind randomized controlled TOPMAST trial evaluated cumulative fluid balance in 70 patients with normal kidney function who had undergone major thoracic surgery [7]. The estimated cumulative fluid balance at $48 \mathrm{~h}$ was $887 \mathrm{~mL}(95 \%$ CI 380-1394) more positive in the Na154 arm, despite almost identical non-study fluid sources and fluid losses through drain outputs. As a result, the fluids' sodium content was considered responsible for an additional fluid retention of $22 \%$ (95\% CI 10-34\%) of its infused volume. Figure 1 shows the cumulative fluid balance encountered in the two studies as reported in the original papers, rescaled for optimal comparison.

\section{Is sodium-induced fluid retention associated with poorer clinical outcomes?}

A positive cumulative fluid balance has long been associated with undesirable outcomes in septic and critically ill patients [5]. In the perioperative setting, restrictive fluid regimens were convincingly shown to be superior to more liberal fluid policies [36, 37]. The specific clinical impact of sodium-induced rather than volume-induced fluid retention is difficult to demonstrate in view of the scarce dedicated research. Yet, various pieces of evidence hint at its clinical importance. First, a body weight gain of 2 to $3 \mathrm{~kg}$ due to sodium-rich perioperative fluid therapy compared to sodium-poor alternatives was shown to be associated with increased perioperative morbidity [38]. Second, a prospective observational study in 50 mechanically ventilated patients showed that a positive sodium balance was associated with a next-day reduction in the $\mathrm{PaO}_{2} / \mathrm{FiO}_{2}$ and increased duration of mechanical ventilation [15]. Interestingly, these adverse respiratory outcomes were not related to the cumulative positive fluid balance. Finally, in TOPMAST, treatment with Na154 was halted in $17 \%$ of cases due to clinical or radiographic fluid overload for which diuretics were needed, compared to $3 \%$ in the Na54 group $(p=0.05)$ [7]. Even less research has addressed the clinical impact of the catabolic generation of urea to improve urine concentration and the importance of providing enough free water to assist in sodium excretion. In view of the extensive use of sodium-rich solutions in the hospital, appropriate scientific efforts are urgently needed. 

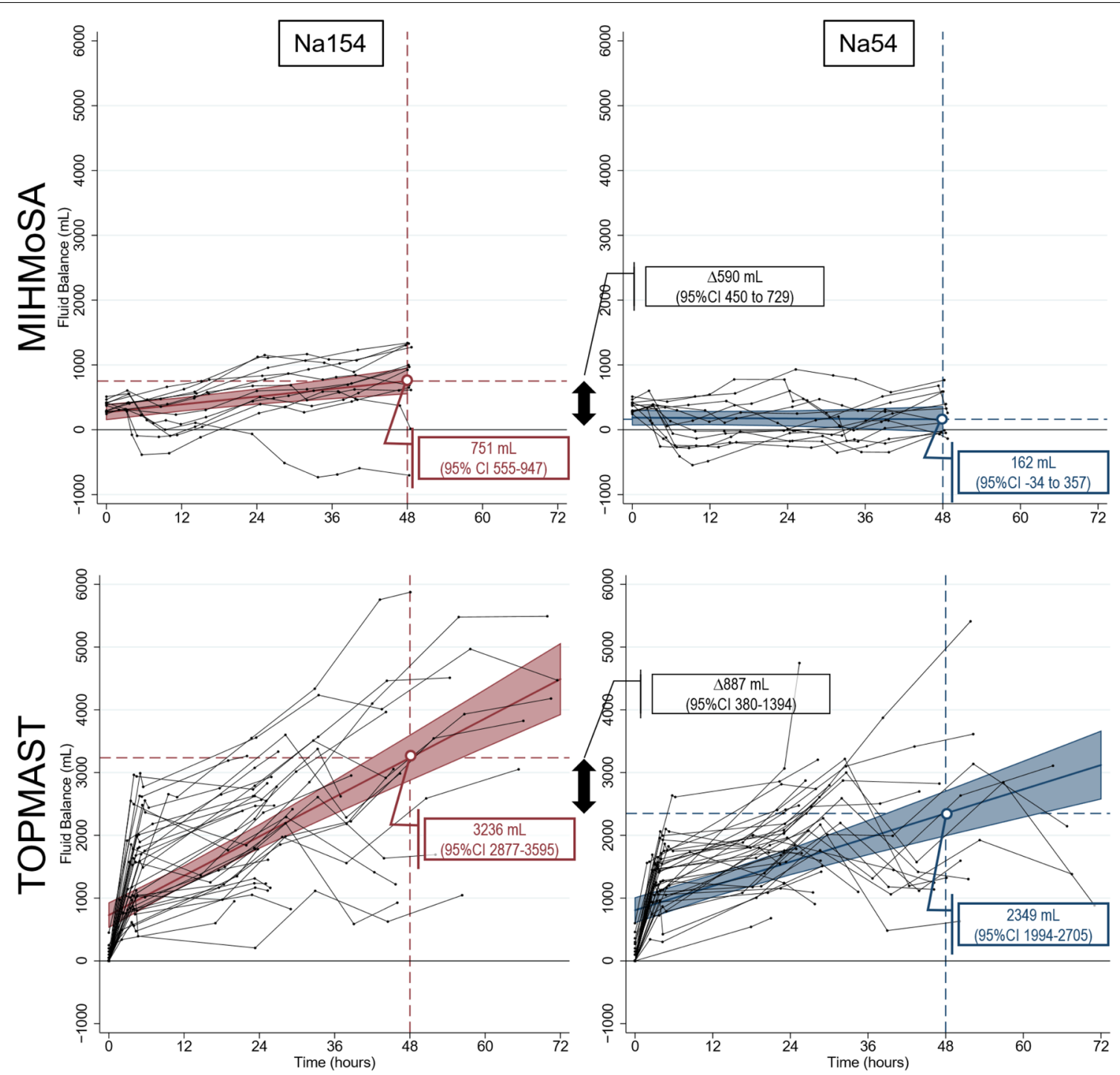

Fig. 1 Cumulative fluid balance of the MIHMOSA and TOPMAST trials. Both in healthy volunteers (MIHMOSA) and in patients undergoing major surgery (TOPMAST), fluid retention was significantly higher in the treatment arm receiving maintenance fluids containing $154 \mathrm{mmol} / \mathrm{L}$ of sodium (compared to $54 \mathrm{mmol} / \mathrm{L}$ ). Compared to healthy subjects, the patient cohort had a more positive fluid balance, no matter the study fluid, partly due to other net fluid input $( \pm 1.5 \mathrm{~L}$ ) and partly due to the physiological response to hypovolemia, capillary leakage, etc. For details: see text. Adapted from Van Regenmortel et al. and Van Regenmortel et al., with permission [7, 8]

\section{Fluid balance needs a balanced view}

It cannot be ignored that a positive fluid balance is often a marker of illness severity rather than the cause of harm itself. Indeed, even a markedly positive fluid balance is frequently unavoidable, as it is not merely the result of imprudent fluid therapy, but also a combination of physiological processes responding to certain clinical realities such as hypovolemia, vasodilation, and capillary leakage. As such, a patient's fluid balance can be positive in the presence of euvolemia, or even intravascular hypovolemia. Figure 1 shows much higher cumulative fluid balances in both TOPMAST treatment arms compared to the healthy volunteers in the MIHMoSA experiment. This difference could not be explained by off-study net fluid input. It seems that, in the TOPMAST study, intravenous fluids were retained by the kidneys to counterbalance vasodilation, hypovolemia and/or the increased endothelial permeability associated with surgery/anesthesia. Neglecting this reality and striving for an absolute "magic number" or even a zero fluid balance could be harmful. The results of the RELIEF trial, in which patients in the restrictive fluid arm were more prone 
to develop AKI, remind us that the pendulum of fluid restriction can easily swing too far [39]. Despite the need for a cautious and nuanced consideration of cumulative fluid balance, the fact remains that iatrogenic fluid overload certainly exists and-in the absence of a more optimal parameter-many clinicians will use it to judge the need for clinical intervention. Therefore, we are convinced it is important to avoid any additional factors that have the potential to further derail fluid balance. Sodiuminduced fluid retention is one of those factors.

\section{Streamlining the sodium pandemonium}

Preventing fluid overload is notoriously difficult, and determining the optimal amount of fluid is one of the most challenging clinical decisions in critically ill and surgical patients. In contrast, avoiding unnecessary sodium overload might be the low-hanging fruit. Reducing the sodium burden could thus be a straightforward and feasible option in the battle against iatrogenic fluid overload. Fortunately, the search for avoidable sources of sodium is not extremely challenging, as two of them are hidden in plain sight.

\section{Step 1: cut the creep!}

Dissolving as many medications as possible in glucose or dextrose $5 \%$ can dramatically reduce unintentional sodium administration. Oral intake or enteral administration could be valuable alternatives to drugs with high oral bioavailabilities. Table 2 provides the results of a medication-per-medication literature search of the most common medicines used in critical care, whether intermittently or continuously through syringe pumps. Notably, the use of $\mathrm{NaCl} 0.9 \%$ as a solvent is mandatory for surprisingly few medications. For the majority, it is simply an unfortunate habit. A prospective before-and-after study in a tertiary ICU demonstrated the feasibility of decreasing the total sodium (and chloride) burdens by intervening in fluid creep and in the type of maintenance fluids [40]. The amount of sodium administered daily decreased by almost half to a median of $109 \mathrm{mmol}$ (IQR 77-288), leading to a decrease in daily fluid balance and electrolyte disturbances.

\section{Step 2: adopt a hypotonic maintenance fluid strategy without losing sight of hyponatremia}

First, we want to emphasize that the necessary amounts of water and electrolytes should ideally be administered orally or enterally. Intravenous maintenance fluid therapy should only be prescribed in situations where patients are able neither to ingest food or fluids nor to receive (par)enteral nutrition. As soon as other sources provide enough free water to excrete sodium and other solutes, maintenance fluids become redundant. On the other hand, banning all maintenance fluids from the hospital or the ICU will lead to many patients being unable to excrete the necessary solutes, especially because of the displacement of intravascular fluid towards the interstitial space. The ensuing risk of acute kidney injury, encountered after a too-restrictive fluid policy, is unacceptable [39]. We want to stress the fact that maintenance fluids are not the same as resuscitation fluids (isotonic by nature, and frequently guided by hemodynamic monitoring) or replacement fluids, which are prescribed to cover lost fluids or ongoing fluid losses, for example in the event of diarrhea, fever, dehydration, losses through different types of surgical drains, and so on $[41,42]$. Maintenance fluids should be prescribed only to cover daily needs for water and electrolytes and should therefore be as close as possible to a healthy dietary intake (Table 1). From that point of view, they should contain free water and their sodium content should be low.

The other side of the coin and the most feared trade-off of a hypotonic maintenance fluid strategy is the occurrence of hyponatremia. This is the reason why maintenance fluids' ideal sodium content remains a matter of heated debate [43-47]. In-hospital hyponatremia mostly develops due to the actions of antidiuretic hormone $(\mathrm{ADH})$, an osmoregulatory hormone that protects against hyperosmolality. In hypovolemia (occult or otherwise), however, volume regulation is physiologically prioritized over osmoregulation. When $\mathrm{ADH}$ is subsequently upregulated in the absence of an osmotic stimulus and the hypovolemia is not treated adequately with replacement or resuscitation fluids, hyponatremia can occur [43]. Pediatric patients are particularly sensitive to the development of symptoms (mainly neurological) caused by this electrolyte disorder. The question remains whether it is justified to advocate the use of isotonic maintenance solutions for all hospitalized patients to avoid hyponatremia in a minority of them. This is especially questionable in the critical care setting, where other sodium sources are present and sodium is measured multiple times daily through point-of-care analysis $[43,45,48,49]$. Currently, there is little proof of clinically relevant maintenance fluid-induced hyponatremia. Even in the pivotal pediatric trial on the subject, no patients developed symptomatic hyponatremia [50]. Seizures were encountered in $7 / 338$ patients $(2 \%)$ in the hypotonic arm, compared to $1 / 338$ patients $(0.3 \%)$ in the isotonic arm $(p=0.07)$, but all instances occurred in patients with known seizure disorders. In the adult patients of the TOPMAST trial, most instances of hyponatremia were mild and none was symptomatic. Bihari et al. showed that a reduction of sodium and chloride in maintenance fluids and fluid creep led to no differences in either the rate or severity of hyponatremia [40]. 
Table 2 Most used medication in the intensive care unit to be diluted for continuous infusion, slow bolus administration or both. The stability of the diluted product is dependent on its end concentration and environmental temperature. The product's stability in its compatible diluent has been confirmed for the conventional administration times and volumes. For detailed data, we refer to each drug's SmPC (summary of product characteristics) or relevant databases

\begin{tabular}{|c|c|c|c|c|}
\hline & $\mathrm{NaCl} 0.9 \%$ mandatory & $\begin{array}{l}\text { G5\% or D5\% or } \mathrm{NaCl} 0.9 \% \\
\text { equally possible }\end{array}$ & $\begin{array}{l}\text { G5\% or D5\% } \\
\text { mandatory }\end{array}$ & $\begin{array}{l}\text { Administration in its } \\
\text { pure form using a } \\
\text { syringe pump feasible }\end{array}$ \\
\hline \multicolumn{5}{|l|}{ Anti-infectives } \\
\hline \multirow{7}{*}{$\begin{array}{l}\text { Continuous or prolonged (4-8 h) } \\
\text { infusion }\end{array}$} & & Benzylpenicillin & & \\
\hline & & Cefepime dihydrochloride & & \\
\hline & & Ceftazidime pentahydrate & & \\
\hline & & Meropenem trihydrate ${ }^{a}$ & & \\
\hline & & Piperacillin-tazobactam & & \\
\hline & & Temocillin & & \\
\hline & & Vancomycin ${ }^{b}$ & & \\
\hline \multirow{10}{*}{$\begin{array}{l}\text { Short infusion (15-90 min, } \\
\text { depending on product) }\end{array}$} & Amoxicillin-clavulanate ${ }^{c}$ & Benzylpenicillin & & \\
\hline & Acyclovir ${ }^{\mathrm{d}}$ & Cefepime dihydrochloride & & \\
\hline & & Ceftazidime pentahydrate & & \\
\hline & & Ciprofloxacin ${ }^{e}$ & & \\
\hline & & Flucloxacillin & & \\
\hline & & Meropenem trihydrate ${ }^{a}$ & & \\
\hline & & Piperacillin-tazobactam & & \\
\hline & & Sulfamethoxazole-trimethoprim ${ }^{f}$ & & \\
\hline & & Temocillin & & \\
\hline & & Vancomycin ${ }^{b}$ & & \\
\hline \multicolumn{5}{|c|}{ Vasoactive and antiarrhythmic medication } \\
\hline \multirow[t]{9}{*}{ Continuous infusion } & Somatostatin & Adrenaline tartrate or $\mathrm{HCl}^{9}$ & Amiodarone $\mathrm{HCl}$ & Isosorbide dinitrate \\
\hline & & Dobutamine $\mathrm{HCl}$ & Norepinephrine ${ }^{k}$ & Labetalol \\
\hline & & Isosorbide dinitrate ${ }^{h}$ & & Nicardipine \\
\hline & & Labetalol & & Nimodipine \\
\hline & & Milrinone & & Urapidil $\mathrm{HCl}$ \\
\hline & & Molsidomine & & \\
\hline & & Nicardipine ${ }^{h}$ & & \\
\hline & & Urapidil $\mathrm{HCl}$ & & \\
\hline & & Clonidine $\mathrm{HCl}$ & & \\
\hline $\begin{array}{l}\text { Short infusion (15-90 min, } \\
\text { depending on product) }\end{array}$ & & Labetalol & Amiodarone $\mathrm{HCl}$ & \\
\hline \multicolumn{5}{|c|}{ Sedatives, analgetics and antiepileptic agents } \\
\hline \multirow[t]{11}{*}{ Continuous infusion } & & Alfentanyl & & Alfentanyl \\
\hline & & Clonidine $\mathrm{HCl}$ & & Fentanyl citrate \\
\hline & & Dexmedetomidine $\mathrm{HCl}$ & & Ketamine \\
\hline & & Fentanyl citrate & & Midazolam HCl \\
\hline & & Ketamine & & Morphine $\mathrm{HCl}$ \\
\hline & & Midazolam HCl & & Sufentanyl citrate \\
\hline & & Morphine $\mathrm{HCl}$ & & \\
\hline & & Remifentanyl & & \\
\hline & & Sufentanyl citrate & & \\
\hline & & Thiopental sodium & & \\
\hline & & Valproate sodium & & \\
\hline \multirow{2}{*}{$\begin{array}{l}\text { Short infusion (15-90 min, } \\
\text { depending on product) }\end{array}$} & Phenytoin sodium & Levetiracetam & & \\
\hline & & Valproate sodium & & \\
\hline
\end{tabular}


Table 2 (continued)

\begin{tabular}{|c|c|c|}
\hline $\mathrm{NaCl} 0.9 \%$ mandatory & $\begin{array}{l}\text { G5\% or D5\% or } \mathrm{NaCl} 0.9 \% \quad \mathrm{G} 5 \% \text { or D5\% mandatory } \\
\text { equally possible }\end{array}$ & $\begin{array}{l}\text { Administration in its pure } \\
\text { form using a syringe pump } \\
\text { feasible }\end{array}$ \\
\hline \multicolumn{3}{|l|}{ Other common medications used in the ICU } \\
\hline \multirow[t]{7}{*}{ Continuous infusion } & Cisatracurium besylate & Bumetanide \\
\hline & $\begin{array}{l}\text { Concentrated electrolytes } \\
(\mathrm{KCl}, \mathrm{MgSO} 4)\end{array}$ & Cisatracurium besylate \\
\hline & Furosemide $^{i}$ & Concentrated electrolytes ${ }^{j}$ \\
\hline & Heparin sodium & Furosemide \\
\hline & $\begin{array}{l}\text { Methylprednisolone sodium } \\
\text { succinate }\end{array}$ & Heparin sodium \\
\hline & N-Acetylcysteine & \\
\hline & Regular insulin & \\
\hline \multirow{5}{*}{$\begin{array}{l}\text { Short infusion (15-90 min, } \\
\text { depending on product) }\end{array}$} & Bumetanide & \\
\hline & $\begin{array}{l}\text { Concentrated electrolytes } \\
(\mathrm{KCl}, \mathrm{MgSO} 4)\end{array}$ & \\
\hline & Furosemide $^{i}$ & \\
\hline & N-Acetylcysteine & \\
\hline & $\begin{array}{l}\text { Methylprednisolone sodium } \\
\text { succinate }\end{array}$ & \\
\hline
\end{tabular}

\section{D5\% dextrose $5 \%$}

G5\% glucose $5 \%$

a Some sources report a stability of less than $4 \mathrm{~h}$ in G5\%

${ }^{\mathrm{b}}$ After reconstitution with aqua

c After reconstitution with aqua or $\mathrm{NaCl} 0.9 \%$

${ }^{d}$ Glucose $5 \%$ possible but probably less stable because of Maillard reaction

e Mostly commercially prediluted, solvent differs by brand

${ }^{f}$ Minimal necessary volume for dilution: $400 \mathrm{mg}+80 \mathrm{mg} / 5 \mathrm{~mL}$ in $75 \mathrm{~mL}$

${ }^{9} \mathrm{pH}$ of $\mathrm{G} 5 \%$ needs to be around 5.5, otherwise reduced stability

${ }^{\mathrm{h}}$ Avoid polyvinylchloride (PVC) when diluted in $\mathrm{NaCl}$ (sorption to PVC $9 \mathrm{pH}$ of G5\% needs to be around)

i Precipitation possible if $\mathrm{pH}<5.5-7$

j Depending on the initial concentration

${ }^{k}$ Although strictly not impossible to dissolve in $\mathrm{NaCl} 0.9 \%, \mathrm{G} 5 \%$ is recommended for protection against significant drug loss due to oxidation

In order to take all the elements above into account when prescribing maintenance fluid therapy, we propose the algorithm in Fig. 2. The starting point is the guideline-recommended dose of $1 \mathrm{mmol}$ of sodium per $\mathrm{kg}$ of body weight and $25 \mathrm{~mL}$ per $\mathrm{kg}$ of fluid volume per day $[42,51]$. Our proposed flowchart accounts for the presence of other fluid sources, for sodium burdens caused by fluid creep and for the risk of hyponatremia caused by suspected or confirmed hypovolemia. The algorithm takes preventive action towards hyponatremia by including a vigilant attitude towards hypovolemia (occult or otherwise) and ongoing fluid losses and more proactive treatment of at-risk patients. Fluid-depleted patients need isotonic resuscitation or replacement fluids before hypotonic maintenance fluids are considered. When fluid status is difficult to assess, we recommend measuring serum sodium at least before the start and after $24 \mathrm{~h}$ of hypotonic maintenance treatment. When hyponatremia ensues, a switch to isotonic maintenance fluids is reasonable.

We again point out that popular balanced solutions such as Ringer's lactate are efficient in preventing hyperchloremia but have little added value over $\mathrm{NaCl}$ $0.9 \%$ in terms of sodium content (Table 1 ). On the other hand, intravenous solutions with low osmolality cause venoirritation, which is the reason that hypotonic fluids $(\mathrm{NaCl} 0.45 \%$ or lower) are almost without exception dissolved in glucose or dextrose. For example, the addition of glucose $5 \%$ increases the osmolality of $\mathrm{NaCl} 0.45 \%$ from a poorly tolerated $154 \mathrm{mOsm} /$ $\mathrm{kg}$ to $432 \mathrm{mOsm} / \mathrm{kg}$ (without changing the tonicity of the fluid). In the absence of other caloric intake, this has the additional advantage of providing a basic level of caloric intake and thereby preventing starvation ketosis. Meanwhile, hyperglycemia is a well-known risk factor for morbidity in critically ill patients and should 


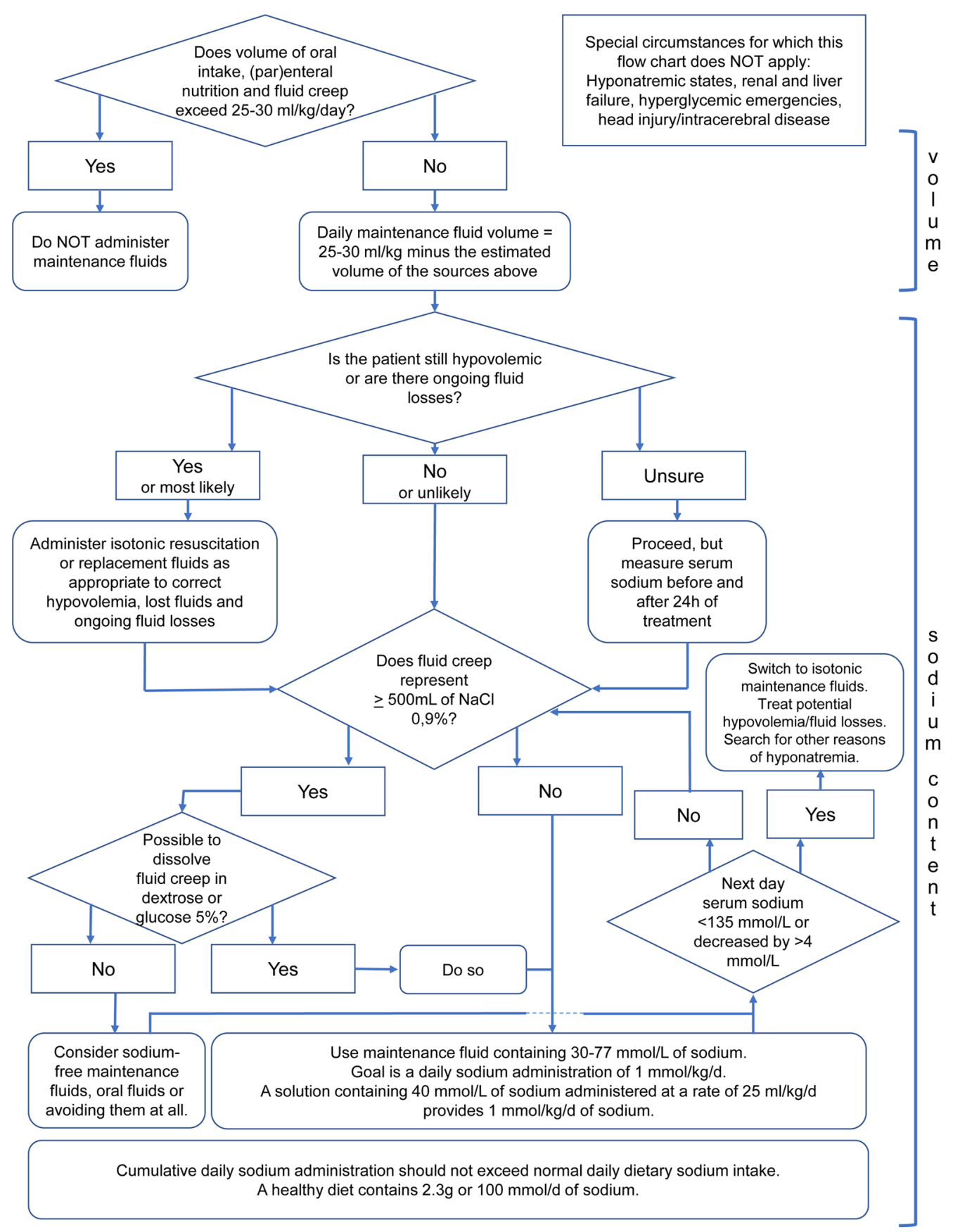

Fig. 2 Suggested maintenance fluid strategy for in-hospital patients, especially those who are at risk of fluid overload or hyponatremia

be prevented by careful glycemic control, especially in critically ill patients $[52,53]$.

\section{Step 3: therapeutic options and the challenge of removing sodium without water}

On a therapeutic level, it is difficult to remove sodium once administered. This is especially true as many diuretics result in diuresis in excess of natriuresis, causing hypernatremia [54]. Just like hyponatremia, hypernatremia is a common problem in the hospital and was found to be an independent predictor of increased mortality $[29,55,56]$. To avoid losing more water than sodium when using loop diuretics, the addition of indapamide has been successfully proposed [57]. Indapamide 
is a thiazide-like diuretic that acts on the $\mathrm{Na}-\mathrm{Cl}$ symporter in the distal convoluted tubule. A prospective single-center study in 40 fluid-overloaded patients in the ICU demonstrated that the co-administration of $1 \mathrm{mg} /$ $\mathrm{kg}$ of furosemide and $5 \mathrm{mg}$ of enteral indapamide led to greater natriuresis compared to treatment with furosemide in monotherapy [57]. Although this concept remains untested in a trial with true clinical endpoints, it seems a feasible therapeutic option. Since thiazide diuretics are associated with an increased incidence of hyponatremia in the treatment of heart failure and lead to greater kaliuresis, these issues should be anticipated and treated appropriately [58].

\section{Conclusions}

Although well-known in experimental research and in the field of hypertension, the dangers of unnecessary or unintentional sodium intake have not yet entered the clinical arena. In the light of the abovementioned findings, this seems unjustified. Evidence supports the hypothesis that high sodium burdens are a separate risk factor for fluid overload and induce a catabolic hormone profile. We therefore call for increased attention to be paid to sodium overload, especially since many of the preventive measures are easy to implement in clinical practice. Ideal starting points include adopting a maintenance fluid strategy that is low in sodium and provides enough free water, and avoiding $\mathrm{NaCl} 0.9 \%$ as the diluent for medication. Caution remains warranted with regard to the development of hyponatremia and hypovolemia. Now that the awareness of iatrogenic volume overload is being incorporated in daily practice and the measures for avoiding it are being pushed to their limits, we are convinced that the battle against sodium-induced fluid overload is the logical next step.

\section{Take home messages}

Unphysiological amounts of sodium, surpassing normal dietary intake, are commonly administered to hospitalized patients through ill-considered maintenance fluid therapy and fluid creep. The notoriously difficult renal handling of this sodium overload leads to potentially harmful fluid retention. We call for increased attention to be paid to this this avoidable problem and suggest the use of low-sodium maintenance fluids (or their avoidance whenever possible) and recommend "cutting the creep" by avoiding $\mathrm{NaCl} 0.9 \%$ as the diluent for medication.

\section{Authors' contributions}

NVR wrote the first draft of the manuscript with all authors, with TL in particular contributing to revisions. LM researched and constructed Table 2 with input from NVR. ER and TVDW double-checked the reported data and Fig. 1.
All authors had full access to all the data. All authors read and approved the final manuscript.

\section{Funding}

No funding was received for the current work. The open access publication costs for this article were covered by an unrestricted educational grant from the International Fluid Academy (https://www.fluidacademy.org).

\section{Declarations}

\section{Competing interests}

Dr Van Regenmortel and Dr Malbrain report speaker's fees from Baxter Belgium. DrVan Regenmortel served on an advisory board on fluid therapy organized by Baxter (2017). Dr Van Regenmortel and Dr Malbrain are chairs of the International Fluid Academy, a non-profit organization promoting education on fluid management and hemodynamic monitoring that received sponsoring from the industry (https://urldefense.proofpoint.com/v2/url? u= http-3A_www.fluidacademy.org\&d=DwIFAg\&c=vh6FgFnduejNhPPD0f__ yRaSfZy8CWbWnlf4XJhSqx8\&r=yAMxyalBUU6FWS_X92e5RF0qgu27J-fAum9 UIH64Ji9P7WvInM6e9epg0HCgDPW7\&m=QkZx0S146DbbMotw8ZpVIFdow G5dHDiMnpuTRIKNbmw\&s=gNrZ_NCIF2Qwfo825mJDWgmsnlgJUrE5ila dovTZjwE\&e=). The other authors have nothing to disclose.

\section{Ethics approval and consent to participate}

For the Ethics Declarations of both the MIHMOSA and TOPMAST studies, we refer to their original publications in the British Journal of Anaesthesia (2017) and Intensive Care Medicine (2019), respectively.

\section{Author details}

${ }^{1}$ Department of Intensive Care Medicine, Antwerp University Hospital, Wilrijkstraat 10 Edegem, B-2650 Antwerp, Belgium. ${ }^{2}$ Department of Intensive Care Medicine, Ziekenhuis Netwerk Antwerpen Campus Stuivenberg, Lange Beeldekensstraat 267, B-2060 Antwerp, Belgium. ${ }^{3}$ Department of Pharmacy, Ziekenhuis Netwerk Antwerpen Campus Stuivenberg, Lange Beeldekensstraat 267, B-2060 Antwerp, Belgium. ${ }^{4}$ Department of Medicine and Surgery, University of Milan-Bicocca, Monza, Italy. ${ }^{5}$ Department of Anaesthesia and Intensive Care Medicine, Niguarda Ca' Granda, Milan, Italy. ${ }^{6}$ StatUa, Center for Statistics, University of Antwerp, Prinsstraat 13, B-2000 Antwerp, Belgium. ${ }^{7}$ Clinical Trial Center (CTC), CRC Antwerp, Antwerp University Hospital, University of Antwerp, Wilrijkstraat 10, B-2650 Edegem, Belgium. ${ }^{8}$ Department of Nephrology, Kliniek Sint-Jan, Kruidtuinlaan 32, B-1000 Brussels, Belgium. ${ }^{9}$ Department of Anesthesia and Critical Care, AOU S. Luigi Gonzaga, Department of Oncology, University of Turin, Turin, Italy. ${ }^{10}$ Faculty of Engineering, Vrije Universiteit Brussel (VUB), Laarbeeklaan 103, 1090 Jette, Belgium. ${ }^{11}$ Department of Intensive Care Medicine, Research VUmc Intensive Care (REVIVE), Amsterdam Medical Data Science (AMDS), Amsterdam Cardiovascular Sciences (ACS), Amsterdam Infection and Immunity Institute (AI\&II), Amsterdam UMC, Vrije Universiteit, Amsterdam, The Netherlands. ${ }^{12}$ Department of Nuclear Medicine, Antwerp University Hospital, Wilrijkstraat 10 Edegem, B-2650 Antwerp, Belgium. ${ }^{13}$ Faculty of Medicine and Health Sciences, University of Antwerp, Universiteitsplein 1 Wilrijk, B-2610 Antwerp, Belgium.

Received: 12 January 2021 Accepted: 3 April 2021

Published online: 17 May 2021

References

1. Self WH, Semler MW, Wanderer JP, Wang L, Byrne DW, Collins SP, et al. Balanced crystalloids versus saline in noncritically ill adults. N Engl J Med. 2018:378(9):819-28.

2. Semler MW, Self WH, Wanderer JP, Ehrenfeld JM, Wang L, Byrne DW, et al. Balanced crystalloids versus saline in critically ill adults. N Engl J Med. 2018;378(9):829-39.

3. Perner A, Haase N, Guttormsen AB, Tenhunen J, Klemenzson G, Aneman A, et al. Hydroxyethyl starch 130/0.42 versus Ringer's acetate in severe sepsis. N Engl J Med. 2012;367(2):124-34.

4. Myburgh JA, Finfer S, Bellomo R, Billot L, Cass A, Gattas D, et al. Hydroxyethyl starch or saline for fluid resuscitation in intensive care. N Engl J Med. 2012;367(20):1901-11. 
5. Vincent JL, Sakr Y, Sprung CL, Ranieri VM, Reinhart K, Gerlach H, et al. Sepsis in European intensive care units: results of the SOAP study. Crit Care Med. 2006;34(2):344-53.

6. Bellamy MC. Wet, dry or something else? Br J Anaesth. 2006;97(6):755-7.

7. Van Regenmortel N, Hendrickx S, Roelant E, Baar I, Dams K, Van Vlimmeren $\mathrm{K}$, et al. 154 compared to $54 \mathrm{mmol}$ per liter of sodium in intravenous maintenance fluid therapy for adult patients undergoing major thoracic surgery (TOPMAST): a single-center randomized controlled double-blind trial. Intensive Care Med. 2019:45(10):1422-32.

8. Van Regenmortel N, De Weerdt T, Van Craenenbroeck AH, Roelant E, Verbrugghe W, Dams K, et al. Effect of isotonic versus hypotonic maintenance fluid therapy on urine output, fluid balance, and electrolyte homeostasis: a crossover study in fasting adult volunteers. $\mathrm{Br} J$ Anaesth. 2017;118(6):892-900.

9. Van Regenmortel N, Verbrugghe W, Roelant E, Van den Wyngaert T, Jorens PG. Maintenance fluid therapy and fluid creep impose more significant fluid, sodium, and chloride burdens than resuscitation fluids in critically ill patients: a retrospective study in a tertiary mixed ICU population. Intensive Care Med. 2018;44(4):409-17.

10. George Institute for Global H, Bihari S, Peake SL, Seppelt I, Williams P, Bersten A, et al. Sodium administration in critically ill patients in Australia and New Zealand: a multicentre point prevalence study. Crit Care Resusc. 2013;15(4):294-300

11. Bihari S, Festa M, Peake SL, Seppelt IM, Williams P, Wilkins B, et al. Sodium administration in critically ill paediatric patients in Australia and New Zealand: a multicentre point prevalence study. Crit Care Resusc. 2014;16(2):112-8.

12. Bihari $\mathrm{S}, \mathrm{Ou} \mathrm{J}$, Holt AW, Bersten AD. Inadvertent sodium loading in critically ill patients. Crit Care Resusc. 2012;14(1):33-7.

13. Intersalt Cooperative Research Group. Intersalt: an international study of electrolyte excretion and blood pressure. Results for 24 hour urinary sodium and potassium excretion. BMJ. 1988;297(6644):319-28.

14. Brown IJ, Tzoulaki I, Candeias V, Elliott P. Salt intakes around the world: implications for public health. Int J Epidemiol. 2009;38(3):791-813.

15. Bihari S, Peake SL, Prakash S, Saxena M, Campbell V, Bersten A. Sodium balance, not fluid balance, is associated with respiratory dysfunction in mechanically ventilated patients: a prospective, multicentre study. Crit Care Resusc. 2015;17(1):23-8.

16. (CHMP) EMA-CFHMP. Questions and answers on sodium used as an excipient in medicinal products for human use. 2017.

17. George J, Majeed W, Mackenzie IS, Macdonald TM, Wei L. Association between cardiovascular events and sodium-containing effervescent, dispersible, and soluble drugs: nested case-control study. BMJ. 2013;347:f6954.

18. Ludwig C. Manuscript notes of lectures, 1869-1870, quoted in a textbook of pharmacology, therapeutics and materia medica. Philadelphia: Lea Brothers and Co.; 1885

19. Bonventre JV, Leaf A. Sodium homeostasis: steady states without a set point. Kidney Int. 1982;21(6):880-3.

20. Early L. Clinical disorders of fluid and electrolyte metabolism. New York: McGraw-Hill; 1972

21. Bankir L, Perucca J, Norsk P, Bouby N, Damgaard M. Relationship between sodium intake and water intake: the false and the true. Ann Nutr Metab. 2017;70(Suppl 1):51-61.

22. Bankir L, Fernandes S, Bardoux P, Bouby N, Bichet DG. Vasopressin-V2 receptor stimulation reduces sodium excretion in healthy humans. J Am Soc Nephrol. 2005;16(7):1920-8.

23. Rakova N, Kitada K, Lerchl K, Dahlmann A, Birukov A, Daub S, et al. Increased salt consumption induces body water conservation and decreases fluid intake. J Clin Invest. 2017;127(5):1932-43.

24. Kitada K, Daub S, Zhang Y, Klein JD, Nakano D, Pedchenko T, et al. High salt intake reprioritizes osmolyte and energy metabolism for body fluid conservation. J Clin Invest. 2017;127(5):1944-59.

25. Kerstens $M N$, van der Kleij FG, Boonstra AH, Sluiter WJ, Koerts J, Navis $G$, et al. Salt loading affects cortisol metabolism in normotensive subjects: relationships with salt sensitivity. J Clin Endocrinol Metab. 2003;88(9):4180-5

26. Choukroun G, Schmitt F, Martinez F, Drueke TB, Bankir L. Low urine flow reduces the capacity to excrete a sodium load in humans. Am J Physiol. 1997;273(5):R1726-33.
27. Rugg C, Strohle M, Treml B, Bachler M, Schmid S, Kreutziger J. ICU-acquired hypernatremia is associated with persistent inflammation, immunosuppression and catabolism syndrome. J Clin Med. 2020;9(9):3017

28. Lindner G, Schwarz C, Funk GC. Osmotic diuresis due to urea as the cause of hypernatraemia in critically ill patients. Nephrol Dial Transplant. 2012;27(3):962-7.

29. Oude Lansink-Hartgring A, Hessels L, Weigel J, de Smet A, Gommers D, Panday PVN, et al. Long-term changes in dysnatremia incidence in the ICU: a shift from hyponatremia to hypernatremia. Ann Intensive Care. 2016;6(1):22.

30. Kotchen TA, Luke RG, Ott CE, Galla JH, Whitescarver S. Effect of chloride on renin and blood pressure responses to sodium chloride. Ann Intern Med. 1983:98(5 Pt 2):817-22.

31. Wilcox CS. Regulation of renal blood flow by plasma chloride. J Clin Invest. 1983;71(3):726-35.

32. Reid F, Lobo DN, Williams RN, Rowlands BJ, Allison SP. (Ab)normal saline and physiological Hartmann's solution: a randomized double-blind crossover study. Clin Sci. 2003;104(1):17-24.

33. Overlack A, Maus B, Ruppert M, Lennarz M, Kolloch R, Stumpe KO. Potassium citrate versus potassium chloride in essential hypertension. Effects on hemodynamic, hormonal and metabolic parameters. Dtsch Med Wochenschr. 1995;120(18):631-5.

34. Lobo DN, Stanga Z, Simpson JA, Anderson JA, Rowlands BJ, Allison SP. Dilution and redistribution effects of rapid 2-litre infusions of $0.9 \%(\mathrm{~W} / \mathrm{V})$ saline and $5 \%(\mathrm{w} / \mathrm{v})$ dextrose on haematological parameters and serum biochemistry in normal subjects: a double-blind crossover study. Clin Sci. 2001;101(2):173-9.

35. Tindall SF, Clark RG. The influence of high and low sodium intakes on post-operative antidiuresis. Br J Surg. 1981;68(9):639-44.

36. Brandstrup $B$, Tonnesen $H$, Beier-Holgersen $\mathrm{R}$, Hjortso $\mathrm{E}$, Ording $\mathrm{H}_{\text {, }}$ Lindorff-Larsen $\mathrm{K}$, et al. Effects of intravenous fluid restriction on postoperative complications: comparison of two perioperative fluid regimens: a randomized assessor-blinded multicenter trial. Ann Surg. 2003:238(5):641-8.

37. Tambyraja AL, Sengupta F, MacGregor AB, Bartolo DC, Fearon KC. Patterns and clinical outcomes associated with routine intravenous sodium and fluid administration after colorectal resection. World J Surg. 2004;28(10):1046-51 (Discussion 1051-2).

38. Lobo DN, Bostock KA, Neal KR, Perkins AC, Rowlands BJ, Allison SP. Effect of salt and water balance on recovery of gastrointestinal function after elective colonic resection: a randomised controlled trial. Lancet. 2002;359(9320):1812-8.

39. Myles PS, Bellomo R, Corcoran T, Forbes A, Peyton P, Story D, et al. Restrictive versus liberal fluid therapy for major abdominal surgery. N Engl J Med. 2018:378(24):2263-74.

40. Bihari S, Prakash S, Potts S, Matheson E, Bersten AD. Addressing the inadvertent sodium and chloride burden in critically ill patients: a prospective before-and-after study in a tertiary mixed intensive care unit population. Crit Care Resusc. 2018;20(4):285-93.

41. Van Regenmortel N, Jorens PG, Malbrain ML. Fluid management before, during and after elective surgery. Curr Opin Crit Care. 2014;20(4):390-5.

42. National Institute for Health and Care Excellence Guideline for Intravenous fluid therapy in adults in hospital (CG174), National Institute for Health and Care Excellence Guideline for Intravenous fluid therapy in adults in hospital (CG174), 2013. 2017.

43. Holliday MA, Ray PE, Friedman AL. Fluid therapy for children: facts, fashions and questions. Arch Dis Child. 2007;92(6):546-50.

44. Leroy PL, Hoorn EJ. Should we use hypotonic or isotonic maintenance intravenous fluids in sick patients? Why a study in healthy volunteers will not provide the answer: response to: effect of isotonic versus hypotonic maintenance fluid therapy on urine output, fluid balance, and electrolyte homeostasis: a crossover study in fasting adult volunteers. Br J Anaesth. 2017;119(4):836-7.

45. Van Regenmortel N, Jorens PG. Effect of isotonic vs hypotonic maintenance fluid therapy on urine output, fluid balance, and electrolyte homeostasis: a crossover study in fasting adult volunteers Reply from the authors. Br J Anaesth. 2017;119(5):1065-7.

46. Lane N, Allen K. Hyponatraemia after orthopaedic surgery. BMJ. 1999:318(7195):1363-4. 
47. Arieff Al. Hyponatremia, convulsions, respiratory arrest, and permanent brain damage after elective surgery in healthy women. N Engl J Med. 1986;314(24):1529-35.

48. Moritz ML, Ayus JC. Maintenance intravenous fluids in acutely ill patients. N Engl J Med. 2015;373(14):1350-60.

49. Ray PE. Neurological complications from dysnatremias in children: a different point of view. Pediatr Nephrol. 2006;21(7):1048-9 (author reply 1050-1).

50. McNab S, Duke T, South M, Babl FE, Lee KJ, Arnup SJ, et al. $140 \mathrm{mmol} / \mathrm{L}$ of sodium versus $77 \mathrm{mmol} / \mathrm{L}$ of sodium in maintenance intravenous fluid therapy for children in hospital (PIMS): a randomised controlled doubleblind trial. Lancet. 2015;385(9974):1190-7.

51. Dietary reference values for food energy and nutrients for the United Kingdom. Report of the panel on dietary reference values of the Committee on Medical Aspects of Food Policy. Rep Health Soc Subj 1991:41:1-210.

52. Vanhorebeek I, Gunst J, Ellger B, Boussemaere M, Lerut E, Debaveye Y, et al. Hyperglycemic kidney damage in an animal model of prolonged critical illness. Kidney Int. 2009;76(5):512-20.

53. van den Berghe $G$, Wouters $P$, Weekers F, Verwaest C, Bruyninckx F, Schetz $M$, et al. Intensive insulin therapy in critically ill patients. N Engl J Med. 2001;345(19):1359-67.
54. Choo WP, Groeneveld AB, Driessen RH, Swart EL. Normal saline to dilute parenteral drugs and to keep catheters open is a major and preventable source of hypernatremia acquired in the intensive care unit. J Crit Care. 2014;29(3):390-4.

55. Tsipotis E, Price LL, Jaber BL, Madias NE. Hospital-Associated Hypernatremia Spectrum and Clinical Outcomes in an Unselected Cohort. Am J Med. 2018;131(1):72-82 e1.

56. Polderman KH, Schreuder WO, Strack van Schijndel RJ, Thijs LG. Hypernatremia in the intensive care unit: an indicator of quality of care? Crit Care Med. 1999;27(6):1105-8.

57. Bihari S, Holt AW, Prakash S, Bersten AD. Addition of indapamide to frusemide increases natriuresis and creatinine clearance, but not diuresis, in fluid overloaded ICU patients. J Crit Care. 2016;33:200-6.

58. Brisco-Bacik MA, Ter Maaten JM, Houser SR, Vedage NA, Rao V, Ahmad $\mathrm{T}$, et al. Outcomes associated with a strategy of adjuvant metolazone or high-dose loop diuretics in acute decompensated heart failure: a propensity analysis. J Am Heart Assoc. 2018;7(18):e009149.

\section{Publisher's Note}

Springer Nature remains neutral with regard to jurisdictional claims in published maps and institutional affiliations.

\section{Submit your manuscript to a SpringerOpen ${ }^{\circ}$ journal and benefit from:}

- Convenient online submission

- Rigorous peer review

- Open access: articles freely available online

- High visibility within the field

- Retaining the copyright to your article

Submit your next manuscript at $\boldsymbol{\nabla}$ springeropen.com 